www.nature.com/pj

\title{
Development of microporous PE films to improve lithium ion batteries
}

\author{
Haruyuki Yoneda ${ }^{1}$, Yoshifumi Nishimura ${ }^{2}$, Yoshinao Doi $^{3}$, Masahiko Fukuda ${ }^{4}$ and Mitsuo Kohno ${ }^{5,6}$ \\ A microporous polyethylene (PE) film has been developed for use as the separator of a lithium (Li) ion secondary battery (LIB). \\ LIBs are necessary in modern society as a power supply for portable equipment such as cellular phones and notebook \\ computers. The greatest problem with using LIBs has been ensuring safety when using a Li compound and a flammable organic \\ electrolytic solution. The most important point for ensuring the safety of LIBs has been using a separator to prevent contact \\ between the cathode and the anode. The Asahi Kasei Corporation has developed the safety function of the separator and \\ improved the performance of the LIB. The manufacture of battery separators made of microporous PE films was studied for PE- \\ solvent systems (two-component phase-separation systems), as well as for new systems in which an inorganic powder was added \\ to the PE and the solvent in this two-component system to produce three-component phase-separation systems. This method is \\ based on thermally induced phase separation.
}

Polymer Journal (2010) 42, 425-437; doi:10.1038/pj.2010.25; published online 21 April 2010

Keywords: LIB; microporous membrane; PE microporous film; phase separation; separator; thermally induced phase separation

\section{INTRODUCTION}

Details of LIB development and separator development

Lithium (Li) ion secondary batteries (LIBs) are a necessary part of the power supply for portable equipment such as cellular phones and notebook computers. The greatest difficulty encountered in spreading the use of LIBs to other applications has been ensuring safety when using a $\mathrm{Li}$ compound with a flammable organic electrolytic solution. The key to ensuring the safety of LIBs has been the use of a safety function in the separator that prevents contact between the cathode and the anode. The Asahi Kasei Corporation developed the safety function of the separator and improved the performance of LIBs. ${ }^{1-5}$ For the safety function, the objective of the development is to provide a shutdown mechanism when the temperature of LIB increases to a certain level (for example, $130^{\circ} \mathrm{C}$ or higher) because of some abnormality. If this temperature is reached, the pores of the separator close by melting and stop the flow of Li ions. To improve the performance of LIBs, a phase-separation method was developed. Using this method, separators with pores of different diameters can be easily manufactured.

A prototype of LIB was first developed in 1983 by Yoshino et al. of the Asahi Kasei Corporation. The Yoshino LIB was the result of research on conductive polyacetylene by Dr Hideki Shirakawa, who received the Nobel Prize for Chemistry in 2000. ${ }^{6-11}$ Yoshino and Sanechika ${ }^{12}$ found that a combination of a polyacetylene anode and a $\mathrm{LiCoO}_{2}$ cathode produced an excellent secondary battery. Subse- quently, Yoshino et al. found that, unlike polyacetylene, carbon that has a special structure was an excellent anode in 1985. This discovery was based on the frontier electron theory of Dr Kenichi Fukui, who received the Nobel Prize in Chemistry in 1981. The prototype of the present $\mathrm{LIB}$ comprised a $\mathrm{LiCoO}_{2}$ cathode and a carbon anode. ${ }^{13}$ Therefore, LIB is the first commercial product resulting from frontier electron theory. ${ }^{14}$ LIBs are based on studies by Dr Hideki Shirakawa and Dr Kenichi Fukui, two Japanese Nobel Laureates in Chemistry.

Safety testing of batteries under severe conditions began in 1986. These tests were geared toward industrialization. The safety of LIBs is very important. LIBs use Li ions and an organic solvent, and ignition due to an abnormal reaction during charge and discharge has been a significant concern. The continued use of LIBs depends on ensuring their safety.

The separator provides the following: (1) insulation between electrodes, (2) a container for the organic electrolytic solution and (3) Li ion permeation. A safety mechanism for this separator requires the following characteristics: (1) insulation, (2) high affinity with the organic electrolytic solution, (3) continuous pores, (4) mechanical strength that remains during manufacturing and use as a thin film, (5) Li ion permeation (charge and discharge) resistance as low as possible (that is, a very large pore diameter) and (6) a function in which, under abnormal conditions, the micropores of the separator become clogged to block Li ion permeation and shut down the current (Figure 1).

${ }^{1}$ R\&D Center, Asahi Kasei Corporation, Fuji-shi, Japan; ${ }^{2}$ Hipore Plant, Asahi Kasei E-Materials Corporation, Moriyama-shi, Japan; ${ }^{3}$ Microza Plant, Asahi Kasei Chemicals Corporation, Fuji-shi, Japan; ${ }^{4}$ Hipore Sales \& Marketing Department, Asahi Kasei Chemicals Corporation, Tokyo, Japan and ${ }^{5}$ Division of Research and Development, Asahi Kasei Corporation, Fuji-shi, Japan

${ }^{6}$ Current address: National Institute of Advanced Science and Technology, 1-18-13, Sotokanda, Chiyoda-ku, Tokyo, 101-0021, Japan.

Correspondence: Dr H Yoneda, R\&D Center, Asahi Kasei Corporation, Samejima, 2-1, Fuji-shi, Shizuoka, 416-8501, Japan.

E-mail: yoneda.hb@om.asahi-kasei.co.jp

Received 22 February 2010; accepted 23 February 2010; published online 21 April 2010 


\section{Operation principle and structure of LIB}

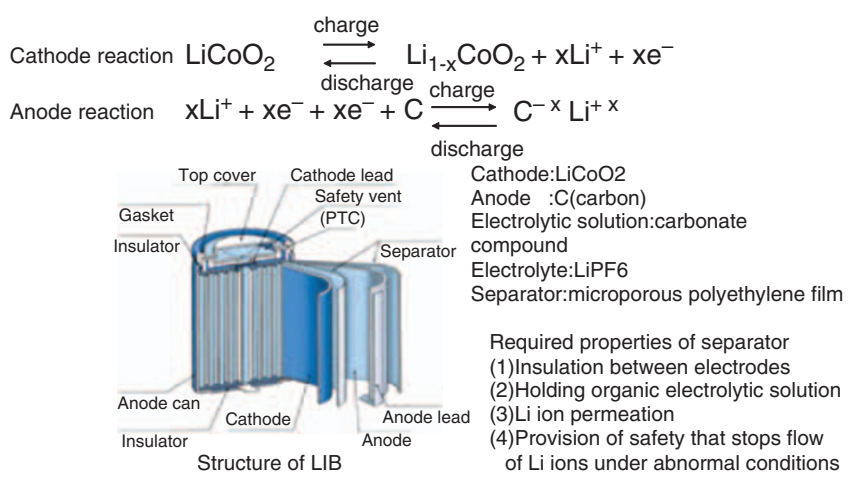

Figure 1 Operation principles and structure of LIB.

The development of a separator that satisfies these required properties has begun.

The operating principle and structure of LIBs are described below.

\section{Development of separator}

Lloyd et al. ${ }^{15,16}$ have interpreted the thermodynamics of a twocomponent phase-separation system with solvents and analyzed the structure of phase-separated membranes that are made of polypropylene. During solid-liquid phase separation, a film is formed, and the solvent is enclosed in a spherulite of this film. During liquid-liquid phase separation, nuclei agglomerate to form cell structures. The size of this cell structure is determined by the product of the nucleus fusion rate and the time the cell spends in the viscosity range in which growth is possible. ${ }^{17}$ Phase separations involving polypropylene and a solvent are well understood, but the phase-separation membranes (the films from which the solvent is extracted) mainly have cell structures. These structures have few continuous pores and are unsuitable for use as a separator. The solvent is dispersed in a spherulite of solid-liquid phase-separation membranes. Even if the solvent were extracted, the produced pores are too small for use as a separator. Moreover, these films have insufficient strength for use as a separator. No attempt has been made to process these films to provide properties suitable for a separator.

Research has been very limited on three-component phase-separation membranes composed of polyethylene (PE), an inorganic powder and a solvent. Only the phase separation of a system that contains a small amount of silica ( $2 \%$ or less) has been studied. ${ }^{18}$ As this system has a small amount of silica, analysis has been performed by the same optical method used to study conventional PE-solvent systems (twocomponent systems). The phase separation of a mixture has been studied for a system composed of a silica surface treated with an organic compound such as stearyl alcohol, polystyrene or toluene. ${ }^{19}$ Phase separation occurs on allowing it to stand at constant temperature, and the system returns to a uniform state again by stirring. It is different from thermally induced phase separation.

No study has been made on the thermally induced phase separation of the PE-inorganic powder-solvent systems that include a large amount of an inorganic powder that cannot be subjected to phaseseparation analysis by an optical method. Moreover, no study has been conducted on the manufacture of a microporous film (specifically, a separator for the LIB) by the phase-separation/extraction/extension method for these three-component systems.

Of the properties required for this separator, the following are the most important: safety (the presence of Li ions), solvent resistance (an organic electrolytic solution must be present), a high porosity ratio and a large pore diameter (to ensure the low conductivity of Li ions), a thin film (to provide a large area) and mechanical strength (by tightly winding thin layers together). PE is optimum for solvent resistance. The battery requires large electrode areas, and the volume of the electrodes and the separator must be limited by tightly winding them together.

The objective of this study was to develop a microporous thin film with a high porosity ratio and a large pore diameter, or a high mechanical strength separator. By increasing the pore diameter, the cycling properties are expected to improve during charge and discharge, and the amount of charge due to repeated charge and discharge should decrease. The discharge properties at low temperature are also expected to improve with a larger pore diameter. The three-component system wet process, for which there has been no research example, was studied with the aim of ameliorating the problems described above. The phase separation of the three-component systems, the relationship between phase separation and the structure of the phase-separation membrane, and the differences in the processing methods (extraction/ extension and extension/extraction) for phase-separation membranes and film properties were clarified to develop a method for manufacturing the target large pore diameter film.

\section{EXPERIMENTAL PROCEDURE}

\section{Samples}

Ultrahigh-molecular-weight PE (UHMWPE) was manufactured by the former Asahi Chemical Industry Co. Ltd (Tokyo, Japan). Its viscosity-average molecular weight (Mv) was 2300000 . High-density PE samples were also manufactured by the former Asahi Chemical Industry Co. Ltd, and their Mvs were 500000,450000 and 280000 . Liquid paraffin was purchased from Matsumura Oil Research Corp. (Kobe, Japan), and its kinematic viscosity at $37.8^{\circ} \mathrm{C}$ was $7.59 \times 10^{-5} \mathrm{~m}^{2} \mathrm{~s}^{-1}$. Dibutyl phthalate (DBP), dioctyl phthalate (DOP), diisodecyl phthalate and ditridecyl phthalate were purchased from Wako Pure Chemical Industries Ltd (Osaka, Japan) and used without further purification. Silica powder VN3 was manufactured by Nippon Silica Industrial Co. Ltd (Tokyo, Japan), and AEROSIL 130, 200 and 300 were manufactured by Nippon Aerosil Co. Ltd (Tokyo, Japan).

\section{Preparation of phase diagram and analysis of phase-separation membranes}

For the preparation of a phase diagram for the two-component phaseseparation system, the system was measured using the standard method for optically obtaining a cloud point. This method involves changing the type of solvent.

To analyze the phase separation of the three-component phase-separation system, a predetermined amount of PE, silica and DOP were placed in a batch type kneader (Labo Plastomill 50C150, Toyo Seiki Seisaku-sho Ltd, Tokyo, Japan). The temperature was increased, and mixing was carried out until the inorganic powder was dispersed into a uniform state. Next, the temperature was decreased with constant stirring, and the relationship between torque and temperature was recorded as a function of time.

Fabrication of two-component mixture (PE/solvent) sheets. A predetermined amount of $\mathrm{PE}$ and a predetermined amount of the solvent were introduced into the batch-type kneader (Labo Plastomill 50C150, Toyo Seiki Seisaku-sho, Ltd), and kneading was performed at a predetermined temperature for a predetermined time. The resulting mixture was pressurized using a press and then cooled to obtain a $\mathrm{PE} /$ solvent mixture sheet.

Analysis of phase-separation membranes. The mixture sheet was immersed in a large amount of methylene chloride to extract the solvent and obtain a phaseseparation membrane. A cross-section and surface of the obtained membrane were observed using an electron microscope.

Three-component mixture (PE/solvent/inorganic powder) sheets. A predetermined amount of PE, silica powder and solvent was introduced into the batchtype kneader (Labo Plastomill 50C150, Toyo Seiki Seisaku-sho, Ltd), and 
kneading was performed at a predetermined temperature for a predetermined time. The resulting mixture was pressurized using a press and cooled to obtain a PE/solvent/inorganic powder mixture sheet.

\section{Fabrication of microporous films}

Extension. Extension was performed at a predetermined temperature by a biaxial stretcher manufactured by Iwamoto Seisakusho Co. Ltd (Kyoto, Japan). Extension was performed under the experimental conditions (for example, the extension rate and extension ratio) set for each time. Samples of all the sheets described above were extended.

Solvent extraction. An extended mixture sheet was fixed to a frame and immersed in a vat containing a large excess of methylene chloride for a predetermined time. The samples were allowed to stand for a predetermined time. Thereafter, they were removed from the vat and dried at room temperature.

Silica powder extraction. A sheet obtained by extracting the solvent from the three-component system sheet was immersed in a large excess of an aqueous solution of caustic soda for a predetermined time, washed with water and then dried at room temperature.

\section{Making of other microporous films}

Other microporous films were produced by methods described in patents. ${ }^{20-25}$

\section{Measuring the physical properties}

Various physical properties were measured. Film thickness was measured by a spring-type dial gauge manufactured by Ozaki Mfg Co. Ltd (Tokyo, Japan). To measure puncture strength, a load was applied to a needle with a $\phi 1 \mathrm{~mm}$ spherical tip shape, and the separator was punctured by lowering the needle. Air permeability was measured using the Gurley method (JIS-P8117 paper and board; determination of air permeance; part 5). In this method, a $645-\mathrm{mm}^{2}$ $\left(1\right.$ inch $\left.^{2}\right)$ film is pressurized by a $567-\mathrm{g}$ inner cylinder, and the time required for $100 \mathrm{ml}$ of air to flow out of the film is measured. Porosity was determined using the following equation: porosity $(\%)=\left[\right.$ volume $\left(\mathrm{cm}^{3}\right)$-weight $(\mathrm{g}) /$ density]/ volume $\left(\mathrm{cm}^{3}\right) \times 100$. The weight and thickness of a microporous film with a predetermined area were measured. Pore diameter was measured by the mercury intrusion method.

\section{RESULTS AND DISCUSSION}

\section{Manufacture of microporous PE films with PE-solvent systems (two-component systems)}

Two-component phase-separation system and film structure. A phase diagram was generated for di-alkyl phthalates, which are liquid-liquid phase-separation systems, using compounds in which the chain length of the alkyl group was changed. These results are shown in Figure 2.

The chain length of the alkyl group of the di-alkyl phthalate increased from butyl (DBP) to octyl (DOP), isodecyl (diisodecyl phthalate) and tridecyl (ditridecyl phthalate) as the compatibility with PE increased. With increasing chain length, the binodal line of phase separation decreased. This decrease was about $80^{\circ} \mathrm{C}$ for tridecyl relative to butyl. Moreover, the monotectic point shifted to the side of the lower PE concentration. The PE concentration of tridecyl was about $30 \%$ less than that of butyl.

PE liquid-liquid phase separation and solid-liquid phase separation membranes were fabricated, and the structure of the membranes was observed. PE with a molecular weight of 280000 was dissolved at $250{ }^{\circ} \mathrm{C}$ in liquid paraffin or in DOP as a solvent at a PE concentration of $35 \mathrm{wt} \%$. This solution was rapidly cooled by immersion in ice water and allowed to stand at room temperature for slow cooling. Cooling the solution produced a phase-separation membrane. A cross-section of the phase-separation membrane from which the solvent was extracted was observed using an electron microscope. The results at $6000 \times$ are shown in the upper part of Figure 3.

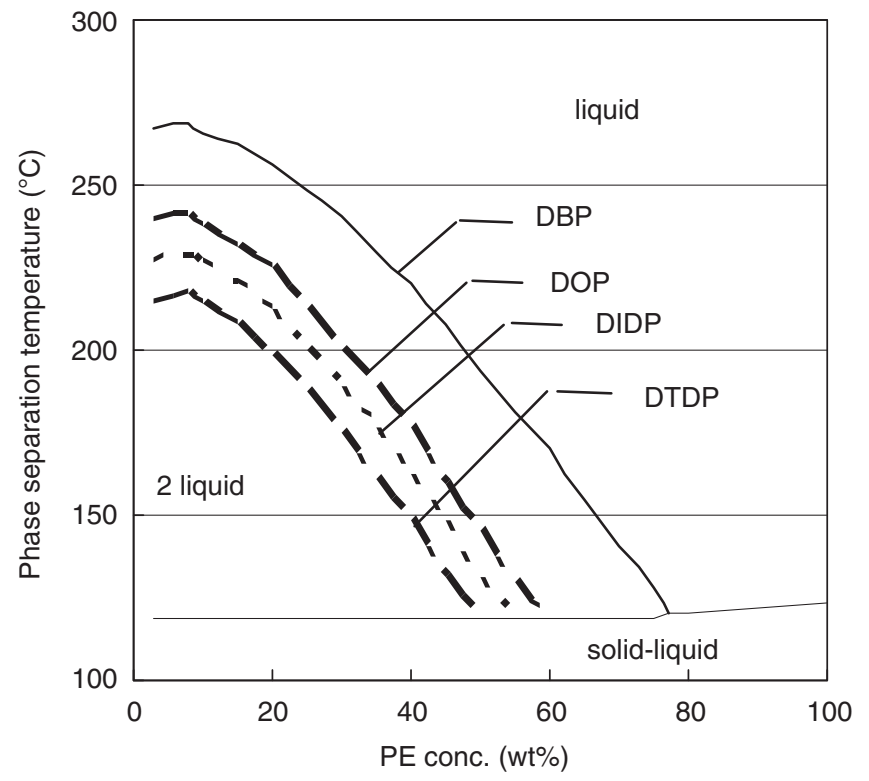

Figure 2 Phase diagram of PE-dialkyl phthalate. ${ }^{2}$ Lines indicate the following dialkyl phthalates: -, dibutyl phthalate (DBP); -.--, dioctyl phthalate (DOP); ...., diisodecyl phthalate (DIDP); - - - , ditridecyl phthalate (DTDP).

After solid-liquid phase separation, cell structures indicating pore formation were rarely observed, but these cell structures were abundant after liquid-liquid phase separation. These results were similar to the results of the polypropylene-solvent systems reported by Lloyd et al. ${ }^{15,16}$ These solvents were evaluated to create the phase diagram in Figure 2. Phase-separation membranes were fabricated by rapid cooling and slow cooling, and cross-sections were observed by an electron microscope. The results are shown in the lower part of Figure 3. In all of the slow cooling systems and in the systems that contain solvents with a low compatibility with PE, only cell structures were present. In the systems that contained solvents with a good compatibility with PE, structures other than cell structures were present in the rapidly cooled samples. These structures are similar to the surface of the solid-liquid phase-separation membrane. When cell structures were present, the diameter of the cell structures was measured from the electron micrographs in Figure 3. These results are shown in Table 1.

The following observations were made: (1) As the compatibility of the solvent with PE decreased, the cell diameter increased. (2) The cell diameter was larger after slow cooling than after fast cooling. (3) As the PE molecular weight decreased, the cell diameter increased.

In liquid-liquid phase-separation membranes, cell structures were recognized (Figure 3). Many nonthrough holes may be present. As the compatibility between $\mathrm{PE}$ and the solvent increased and the PE molecular weight increased, the cell structures decreased (Figure 3 and Table 1).

No cell structures were recognized in the solid-liquid phaseseparation membrane. Instead, very minute pores were seen (Figure 3). The liquid-liquid phase-separation membrane in which the nonthrough holes are dominant is unsuitable for use as a separator, and the pores of the solid-liquid phase-separation membrane were too small to function as the pores of the separator. The phase-separation membrane also has insufficient strength for a separator (described later in Table 2). Therefore, extension was performed to change the pore structures and increase the strength. 
Slow cooling

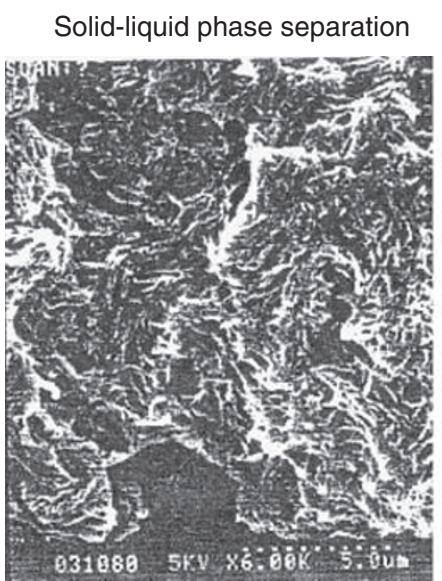

Liq.paraffin
Liquid-liquid phase separation

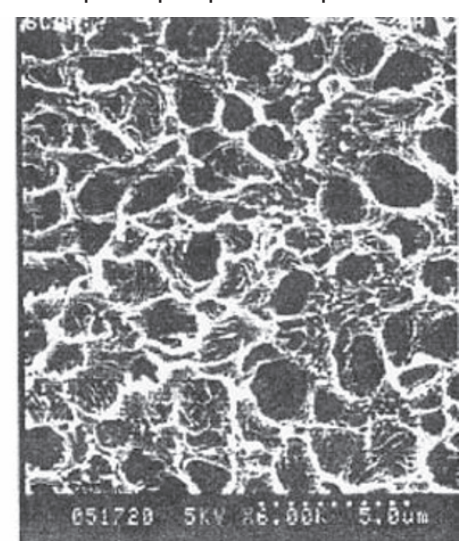

DOP

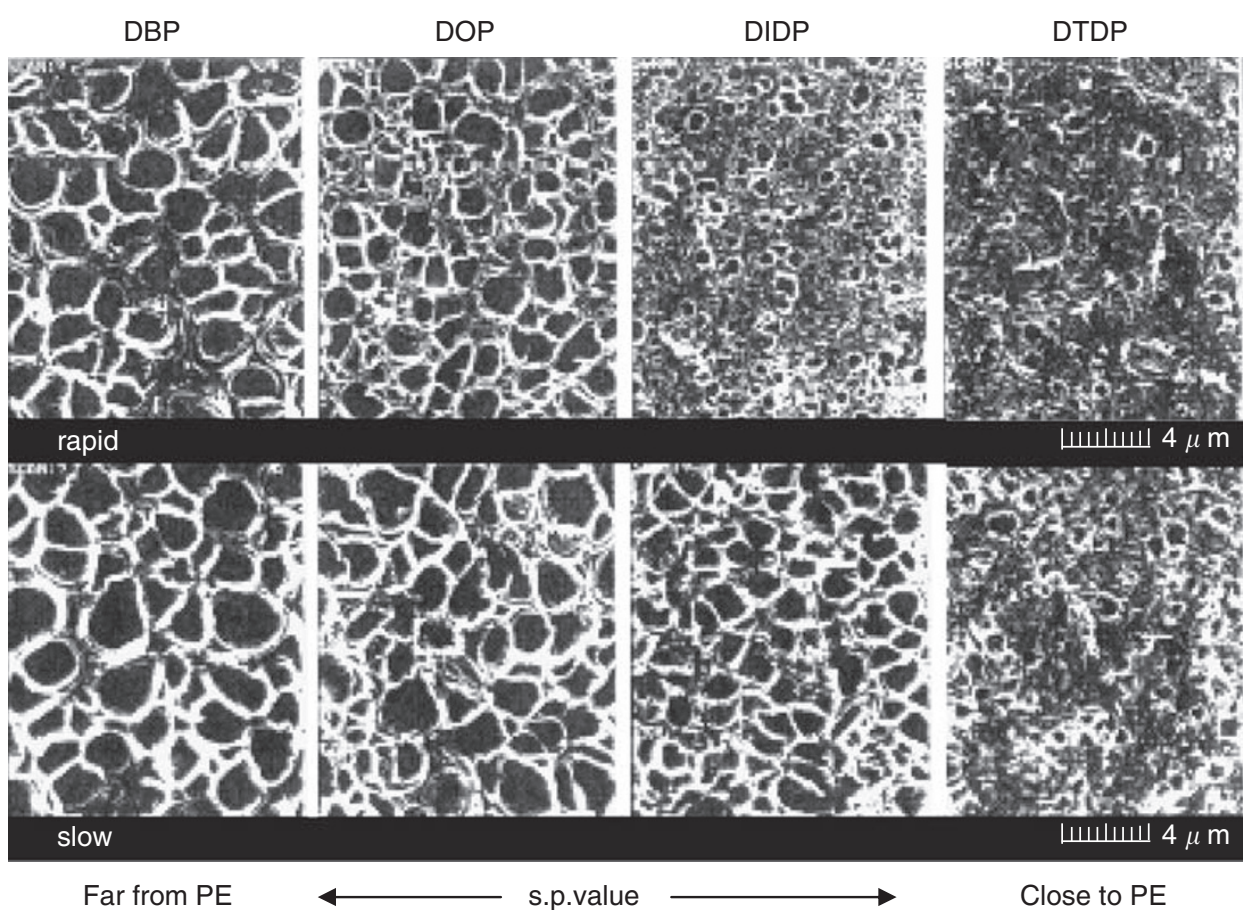

Figure 3 Scanning electron micrograph of a cross-section of the PE phase-separation membrane. ${ }^{2}$ Slow cooling rate: $15^{\circ} \mathrm{C} \mathrm{min}-1 .\left(230^{\circ} \mathrm{C} \rightarrow 100^{\circ} \mathrm{C}\right)$; rapid cooling rate: $50^{\circ} \mathrm{C} \mathrm{min}^{-1}\left(230^{\circ} \mathrm{C} \rightarrow 100^{\circ} \mathrm{C}\right)$; $\mathrm{Mv}$ of PE: $2.8 \times 10^{5}$; concentration of PE: 35 wt $\%$.

Extended films. Pressed sheets (about $550 \mu \mathrm{m})$ were fabricated from the liquid-liquid phase and solid-liquid phase-separation systems containing $\mathrm{PE}$ and a different predetermined solvent. The phaseseparation membranes were subjected to two cycles of extension/ extraction. Extension was performed without solvent extraction, thereafter solvent extraction was performed. Next, extraction/extension was performed to extract the solvent from the phase-separation membrane, thereafter extension was performed again. The properties of the resulting films were measured. These results are shown in Table 2.

Compared with unextended films (phase-separation membranes), both extension/extraction films and extraction/extension films have high puncture strength per unit thickness, and pore structures through which air could pass were present in the extended films. The air permeability of phase-separation membranes was $10000 \mathrm{~s}$ or more, and they have a much lower air permeability than extended films. The systems with extension/extraction were stronger than the systems with extraction/extension but had a smaller pore diameter. In the systems with extraction/extension, when $5 \times 5$ times extensions were performed, a break occurred during extension. A stable extension was performed only up to a $3 \times 3$ times extension. Results for the $3 \times 3$ times extensions are shown in Table 2. Therefore, systems with extraction/extension (particularly in the liquid-liquid phase-separation system) contain large pores because of the extraction of the solvent-rich phase before extension. Extension was not sufficiently performed, and pore formation based on the pores progressed. A high-ratio extension led to film break because of extreme pore formation. In the other systems with extension/extraction, the 
extended film was dense, and the solvent was not extracted. Extension was efficiently performed in these systems, and the strength was improved. No pores formed as a result of extension, and the pore diameter was small. The differences between extraction/extension and extension/extraction processes are greater than the differences in the structure of the phase-separation membrane (that is, the difference due to the solvent used or the difference between liquid-liquid phase separation and solid-liquid phase separation) (Table 2).

Extension ratio, PE molecular weight and mechanical strength. The relationship between the extension ratio and mechanical strength (puncture strength) of microporous films fabricated using the extension/extraction process was examined. PE with different molecular weights was used, and extension was performed by changing the extension ratio. The relationship between the extension ratio and puncture strength is shown in Figure 4.

In PE (Mv: 280000 and 450000 ), puncture strength increased proportionally to the extension ratio in the range of $3 \times 3$ times to $10 \times 10$ times. A high extension ratio increased the strength. In the extension ratio range from $3 \times 3$ (nine times) to $10 \times 10$ (100 times), strength increased with an increase in the molecular weight up to a PE molecular weight of 450000 . The increase in strength was small compared with the increase in the extension ratio in the range of UHMWPE (molecular weight: 2300000 ). For the 100 times extension, the puncture strength decreased in the UHMWPE range compared with that for the PE molecular weights of 280000 and 450000 . The entanglement of UHMWPE might not be sufficient for the PE/

Table 1 Effects of molecular weight of $\mathrm{PE}$, cooling rate and solvent on cell diameter ${ }^{2}$

\begin{tabular}{cccc}
\hline Mv of $P E^{\mathrm{a}}$ & Cooling rate & Solvent & Cell diameter $(\mu \mathrm{m})$ \\
\hline $2.8 \times 10^{5}$ & Slow $^{\mathrm{b}}$ & DBP & $1.0-3.8$ \\
& & DOP & $1.0-2.5$ \\
& & DIDP & $1.0-2.5$ \\
& Rapid & DTDP & $0.6-1.6$ \\
& & DBP & $0.9-2.5$ \\
& & DOP & $0.9-2.2$ \\
& & DIDP & $0.3-1.6$ \\
$1.0 \times 10^{5}$ & Slow & DTDP & -0.6 \\
& & DOP & $1.0-2.5$ \\
& & & $0.6-1.9$ \\
& & & -1.2 \\
\hline
\end{tabular}

Abbreviations: DBP, dibutyl phthalate; DIDP, diisodecyl phthalate; DOP, dioctyl phthalate; DTDP, ditridecyl phthalate; Mv, viscosity-average molecular weight; $\mathrm{PE}$, polyethylene.

aPE concentration of $35 \mathrm{wt} \%$.

bSlow cooling rate of $15^{\circ} \mathrm{C} \mathrm{min}^{-1}\left(230^{\circ} \mathrm{C} \rightarrow 100^{\circ} \mathrm{C}\right)$.

CRapid cooling rate of $50^{\circ} \mathrm{C} \mathrm{min}^{-1}\left(230^{\circ} \mathrm{C} \rightarrow 100^{\circ} \mathrm{C}\right)$ liquid paraffin systems, and alignment by extension was not successful. Thus, no alignment contributed to the strength. Had a method been found in which UHMWPE and liquid paraffin were mixed well without decreasing the molecular weight of the PE, the strength would have improved further.

Manufacture of microporous PE films by two-component method conclusions. Seven major conclusions were reached about this manufacturing process. (1) Phase diagrams for PE-solvent systems were generated, and phase-separation temperature data can be arranged by compatibility between the PE and solvents. (2) During liquid-liquid phase separation, cell structures were mainly produced. (3) In solidliquid phase separation, no cell structures were found. (4) For the extension of phase-separation membranes, the extension effect by extension/extraction was greater than that for extraction/extension. (5) In both extraction/extension and extension/extraction, the pore diameter for the extension of the solid-liquid phase-separation membrane was smaller than that for the extension of the liquidliquid phase-separation membrane. (6) The difference in the extension process (extraction/extension or extension/extraction) was greater than the difference in the structure of the phase-separation membrane before extension, and the study of the extension was important. (7) As a result of studying the extension/extraction of the solid-liquid phaseseparation membrane, there was an improvement in the puncture strength (extension effect) up to an extension ratio of about 100 times.

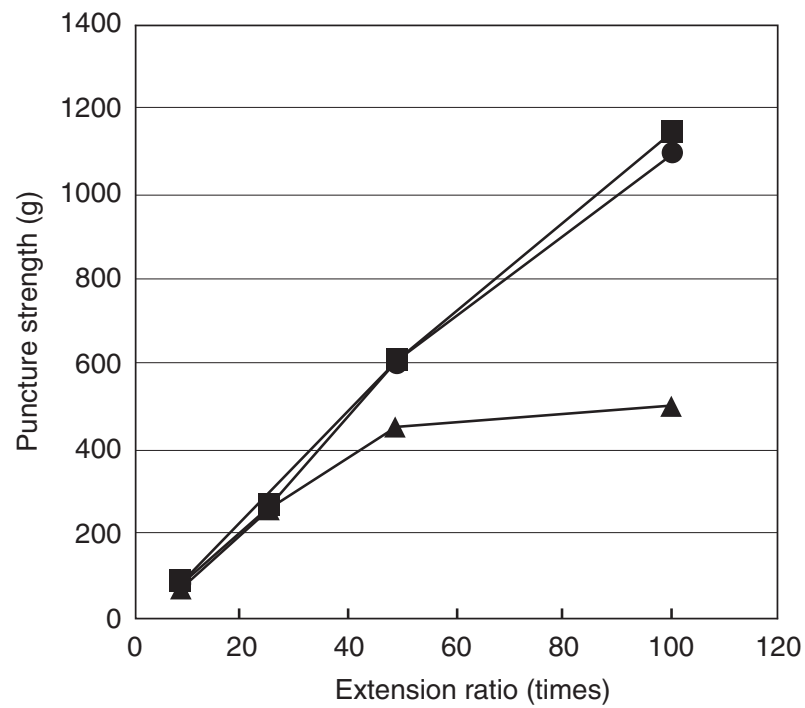

Figure 4 Effects of molecular weight on the relationship between extension ratio and puncture strength. ${ }^{2}$ Symbols indicate the molecular weight of PE. •: $2.8 \times 10^{5} ; \boldsymbol{\square}: 4.5 \times 10^{5} ; \boldsymbol{\Delta}: 2.3 \times 10^{6}$

Table 2 Effects on the preparation process on the properties of membranes made by the phase- separation or extension process. ${ }^{2}$

\begin{tabular}{|c|c|c|c|c|c|c|c|}
\hline Process & Solvent & Extension ratio & $\begin{array}{l}\text { Thickness } \\
(\mu \mathrm{m})\end{array}$ & $\begin{array}{l}\text { Puncture strength } \\
\qquad\left(g \mu m^{-1}\right)^{\mathrm{a}}\end{array}$ & $\begin{array}{c}\text { Pore diameter } \\
(\mu \mathrm{m})\end{array}$ & Porosity (\%) & $\begin{array}{c}\text { Air permeability } \\
\text { (s per } 100 \mathrm{ml} \text { ) }\end{array}$ \\
\hline \multirow[t]{2}{*}{ Extraction } & DOP & & 553 & $<1$ & & 40 & $>10000$ \\
\hline & liq. paraffin & & 558 & $<1$ & & 35 & $>10000$ \\
\hline \multirow[t]{2}{*}{ Extraction/extension } & DOP & $3 \times 3$ & 73 & 4.3 & 0.3 & 50 & 200 \\
\hline & liq. paraffin & $3 \times 3$ & 78 & 4.2 & 0.1 & 51 & 250 \\
\hline \multirow[t]{2}{*}{ Extension/extraction } & DOP & $5 \times 5$ & 24 & 21.3 & 0.08 & 42 & 400 \\
\hline & liq. paraffin & $5 \times 5$ & 25 & 20.8 & 0.05 & 38 & 500 \\
\hline
\end{tabular}

Abbreviations: DOP, dioctyl phthalate; liq., liquid.

aThis puncture strength value is measured in terms of puncture strength or thickness. 
Manufacture of microporous films with PE-solvent-inorganic powder systems (three-component systems)

Three-component system phase-separation analysis. A phase diagram of a typical PE-solvent system was generated by checking the optical cloud point, but this system contains a large amount of an inorganic powder. Therefore, analysis by this method was impossible. A method for measuring the phase-separation state of a three-component system was devised in this study for the first time. A predetermined amount of PE, an inorganic powder and a solvent were introduced into a Plastomill. The temperature was increased while kneading until the inorganic powder was dispersed, and the PE and the solvent were uniform. Next, the temperature was decreased with continued kneading, and torque was measured. With a decrease in temperature, the uniform phase changes to a liquid-liquid two-phase mixture, and an inflection point in the torque was seen. Usually, in a single polymer system, only a monotonous increase in torque occurs with a decrease in temperature. The temperature at which a decrease in torque starts was defined as the starting phase-separation temperature, and the temperature at which an increase in torque begins to be seen again was defined as the phase-separation ending temperature. Using the method described in the Experimental procedure section, composition was measured (Figure 5) and the sample was heated to a temperature of $250{ }^{\circ} \mathrm{C}$ while stirring. After stirring for $5 \mathrm{~min}$, the heating was stopped, and the temperature was decreased with constant stirring. The torque at this time was measured. The measured torque-temperature curves of the three-component and two-component systems are shown in Figure 5.

The starting phase-separation temperature of the three-component system was about $12^{\circ} \mathrm{C}$ lower than that of the two-component system. An analysis was performed using the binodal line of the PE concentration and the phase-separation temperature in the phase diagram for the PE-DOP two-component phase separation. ${ }^{2} \mathrm{~A}$ decrease of about $12{ }^{\circ} \mathrm{C}$ in phase-separation temperature is assumed to correspond to an increase of about $5 \%$ in PE concentration (that is, a decrease of about $5 \%$ in DOP).

Changes in the starting phase-separation temperature by this torque method depended on the composition ratio of the three-component system. The following seven types of three-component system were examined: (1) a standard composition with a PE/DOP/silica (VN3) weight ratio of 44:41:15, (2 and 3 ) two types of composition in which

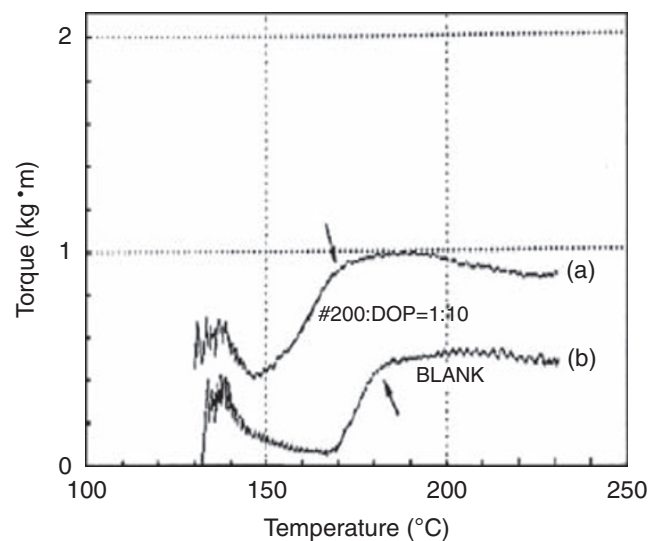

Figure 5 Torque vs temperature of two- and three-component systems. ${ }^{1}$ (a) A three-component system containing PE (30wt\%), DOP (64wt\%) and silica ( 6 wt\%; surface area of silica: $200 \mathrm{~m}^{2} \mathrm{~g}^{-1}$ ) and (b) a two-component system containing PE (30 wt\%) and DOP (70 wt\%). Arrows show the starting temperature of phase separation. the weight ratio of $\mathrm{PE} / \mathrm{DOP}$ was fixed and the weight of silica was changed by about $\pm 20 \%$, ( 4 and 5 ) two types of composition in which the weight ratio of the PE/silica was fixed and the weight of DOP was changed by about $\pm 15 \%$, and ( 6 and 7 ) two types of composition in which the weight ratio of the DOP/silica was fixed and the weight of PE was changed by about $\pm 15 \%$. These systems were fabricated, and the starting phase-separation temperature was measured. The relationship between this starting phase-separation temperature and $\mathrm{PE} /(\mathrm{PE}+\mathrm{DOP})$ in $\mathrm{PE} / \mathrm{DOP} /$ silica is shown in Figure 6.

Three major results were observed: (1) The starting phase-separation temperature decreased with an increase in silica. (2) The starting phase-separation temperature increased with a decrease in silica. (3) An increase and decrease in the amount of PE and the amount of DOP (without an increase and decrease in the amount of silica) were similar to the typical changes in the PE concentration of PE and DOP. The starting phase-separation temperatures of these cases (a change in the amount of PE and a change in the amount of DOP) were slightly different, and the curves gradually decline to the right, as in the twocomponent phase-separation curve (Figure 3).

In the phase separation of these three-component systems, the apparent solvent amount is assumed to decrease because the silica absorbs the solvent. The following three results were determined from Figure 6. (1) The phase-separation temperature decreases when the silica concentration increases because the amount of absorbed solvent increases because of increased silica. Therefore, the amount of solvent that substantially involved with PE during the phase separation decreased. As a result, the apparent PE concentration increased, and the phase-separation temperature decreased. (2) A decrease in silica leads to a decrease in the apparent PE concentration and an increase in phase-separation temperature. (3) Changes in the amount of PE and the amount of DOP were similar to the usual change in $\mathrm{PE}$ concentration in PE and DOP.

To examine the effect of silica on phase-separation temperature and phase-separation rate, silica samples with different surface areas (130, 200 and $300 \mathrm{~m}^{2} \mathrm{~g}^{-1}$; AEROSIL) were used, and the phase-separation

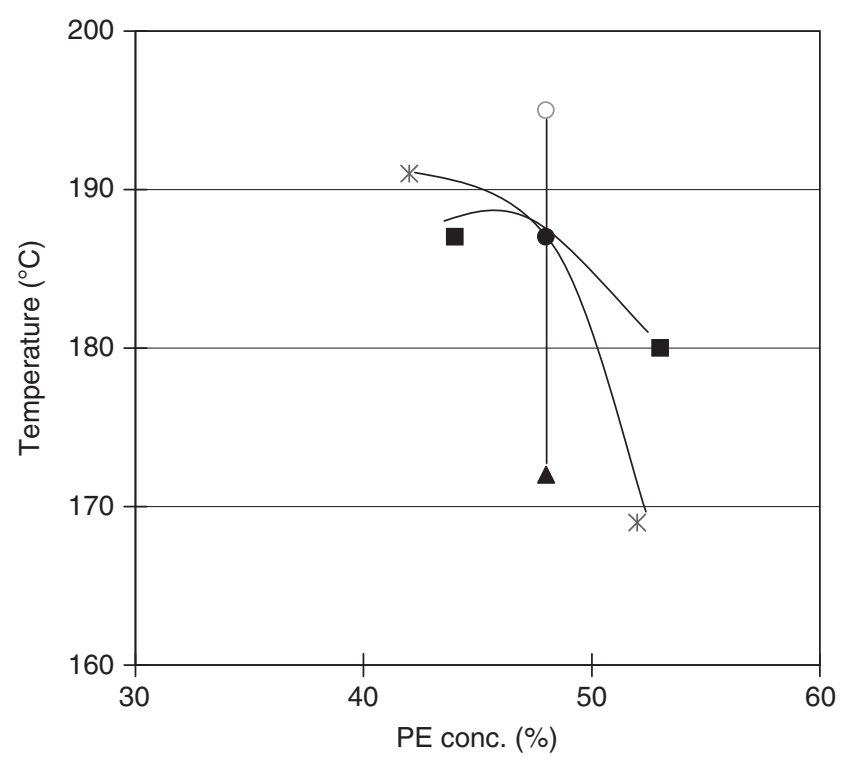

Figure 6 Starting temperature of phase separation for three-component systems. ${ }^{1}$ Symbols indicate the composition. $\bullet$ : standard composition; $\bigcirc$ : low silica wt\%; $\boldsymbol{\Delta}$ : high silica wt\%; $\mathbf{\square}$ : high PE wt\%; *: high or low DOP $w t \%$. 
state was measured and compared with that of the two-component system. These results are shown in Figure 7.

Four major observations were made: (1) When the surface area of the silica was changed from 130 to $300 \mathrm{~m}^{2} \mathrm{~g}^{-1}$, a slight change in the starting phase-separation temperature (about $175^{\circ} \mathrm{C}$ ) was seen. In addition, little change was seen in the phase-separation ending temperature (about $145^{\circ} \mathrm{C}$ ). This measurement was not as accurate as the measurement of the starting temperature. (2) Torque increased with an increase in the surface area of silica over the entire temperature range. (3) The rate of phase separation for silica with a surface area of $300 \mathrm{~m}^{2} \mathrm{~g}^{-1}$ was slower than that for silica with a surface area of $130 \mathrm{~m}^{2} \mathrm{~g}^{-1}$. (4) The phase-separation rate of the three-component system that contains silica with a surface area of $300 \mathrm{~m}^{2} \mathrm{~g}^{-1}(\# 300$ torque curve in Figure 7) has a smaller slope and was slower than the phase-separation rate of the two-component system (REF torque curve in Figure 7).

Both the starting phase-separation temperature and the end temperature were the same, regardless of the surface area of the silica, because the solvent was absorbed by the silica rather than adsorbed on the silica surface. The amount of solvent absorbed depended on the weight of silica. Further, the silica absorbed a certain amount of DOP before the start of phase separation. Our assumption from the results in (2) and (3) was as follows: As the surface area of silica increased, the viscosity (torque) of the three-component system increased, and as the viscosity of the system increased, the rate of phase separation became slower, the decrease in torque was slow and the slope was small. However, no significant difference in the phase-separation rate was observed between 130 and $200 \mathrm{~m}^{2} \mathrm{~g}^{-1}$ silica, and no clear conclusion was obtained.

When the three-component system (the system with a surface area of $300 \mathrm{~m}^{2} \mathrm{~g}^{-1}$ ) was compared with the two-component system with the same viscosity (the PE/DOP composition ratio of 34.6/65.4), the two-component system had nearly the same viscosity as the threecomponent system at $230{ }^{\circ} \mathrm{C}$, and the three-component system had a much slower phase-separation rate. The effect of decreasing the phaseseparation rate was recognized in silica. The extent of the effect depended on the viscosity of the system. Three-component systems had a slower rate even in the low-viscosity systems that contained

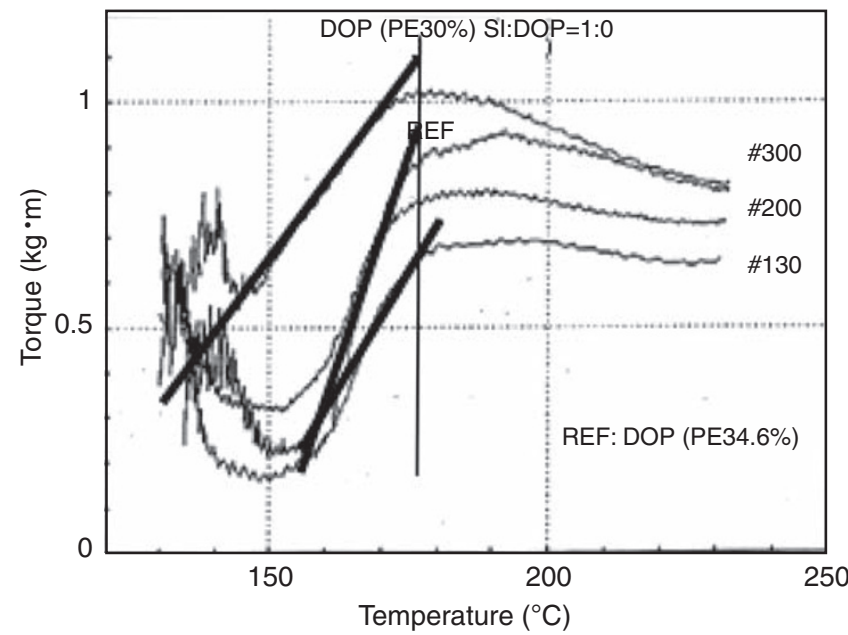

Figure 7 Effects of silica surface area on the phase-separation rate and temperature of a two-component system. ${ }^{1}$ The heavy line shows the rate of phase separation and the light line shows the phase separation starting temperature. \#130, \#200 and \#300 exhibit a three-component system, and 130,200 and 300 show the surface area of the silica. additional silica (that is, the systems with a surface area of 130 and $200 \mathrm{~m}^{2} \mathrm{~g}^{-1}$ ).

For the first time, the addition of silica was observed to slow the phase-separation rate.

To examine the morphology of the three-component and twocomponent films, cross-sections of both phase-separation membranes were compared. The electron microscopy results are shown in Figure 8.

In two-component films, large $(1-3 \mu \mathrm{m})$ cell structures were observed after slow cooling, and small (about $1 \mu \mathrm{m}$ ) cell structures were seen after rapid cooling. In three-component films, no cell structures were seen. The size of the cell structures of the twocomponent liquid-liquid phase-separation system (DOP) has already been described. ${ }^{2}$

Few cell structures were observed in three-component films. The growth of these cell structures is represented by the product of the phase-separation rate, and the time in the viscosity range (temperature range) in which growth is possible. ${ }^{17}$ The phase-separation rate was fast in the two-component systems, but the phase-separation rate was slow in the three-component systems. Therefore, the temperature of the system decreased to the crystallization temperature of the PE solution without the fusion of nuclei (the growth of cell structures), and crystallization occurred without the growth of cell structures. The resulting film structure does not contain cell structures.

To examine the dispersed state of silica in the three-component phase-separation membrane, silica was extracted with $\mathrm{NaOH}$, and the membrane was examined. Little change was seen in the structure of the film before and after the extraction of silica (electron micrograph not shown). The primary particle diameter of the silica used was $0.01-$ $0.02 \mu \mathrm{m}$. No change occurred in the structure before or after extraction, indicating that the silica is dispersed as primary particles and does not aggregate.

Developing a film-manufacturing process. A film obtained by threecomponent phase separation was processed by the following two methods: (1) an extension/extraction process in which extension

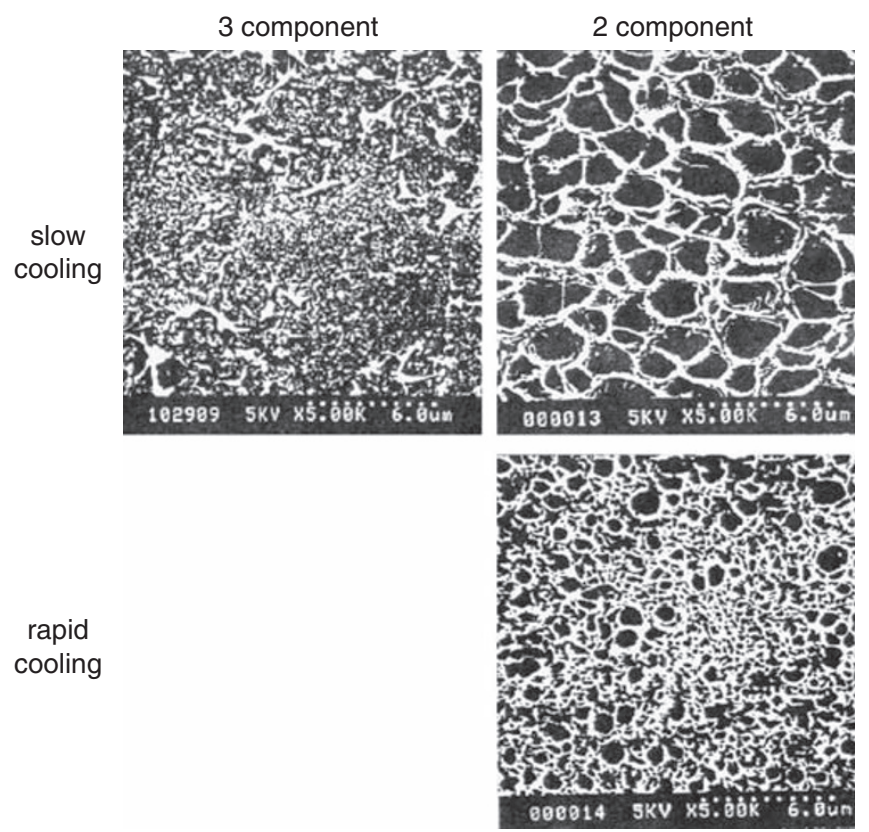

Figure 8 Morphology of the PE phase-separation membrane prepared from two- and three-component systems. ${ }^{1}$ 
was performed without the extraction of the solvent and the silica; and (2) the solvent and the silica were extracted from the phase-separation membrane and then extension was performed. The effect of these processes on the film properties was examined. The results are shown in Table 3.

Two important observations were made: (1) In the case of the extension/extraction process, the pore diameter was small, and the strength was high. (2) In the case of extraction/extension, the pore diameter was at least four times larger than the pore diameter in the first process, and the strength was not as high. These differences between processes were similar to the results of processing the twocomponent phase-separation membrane. ${ }^{2}$

The extension rate and extension ratio of phase-separation membranes with the standard three-component composition were measured. Phase-separation membranes with a thickness of about 100, 200 and $300 \mu \mathrm{m}$ and films obtained by extracting the solvent and the silica from the phase-separation membranes were prepared and subjected to a $3 \times 3$ times extension at three rates (10, 100 and $300 \%$ per second). The relationship between film thickness after extension (after extraction was performed when the phase-separation membrane was directly extended) and puncture strength is shown in Figure 9.

Using Figure 9, interpolation and extrapolation were performed at $25 \mu \mathrm{m}$ to obtain puncture strength at $25 \mu \mathrm{m}$. The relationship between puncture strength at $25 \mu \mathrm{m}$ and extension rate is shown in Figure 10.

When the extension rate was increased, an improvement in strength was seen for both processes. This effect was slightly greater for the

Table 3 Physical properties of the membranes made by different processes $^{1}$ (extraction/extension and extension/extraction)

\begin{tabular}{lcccc}
\hline & $\begin{array}{c}\text { Thickness } \\
(\mu \mathrm{m})\end{array}$ & $\begin{array}{c}\text { Porosity } \\
(\%)\end{array}$ & $\begin{array}{c}\text { Puncture } \\
\text { strength } \\
(g)\end{array}$ & $\begin{array}{c}\text { Pore } \\
\text { diameter } \\
(\mu \mathrm{m})\end{array}$ \\
\hline Extraction/extension & 30 & 48 & 300 & 0.51 \\
Extension/extraction & 26 & 40 & 410 & 0.12 \\
\hline
\end{tabular}

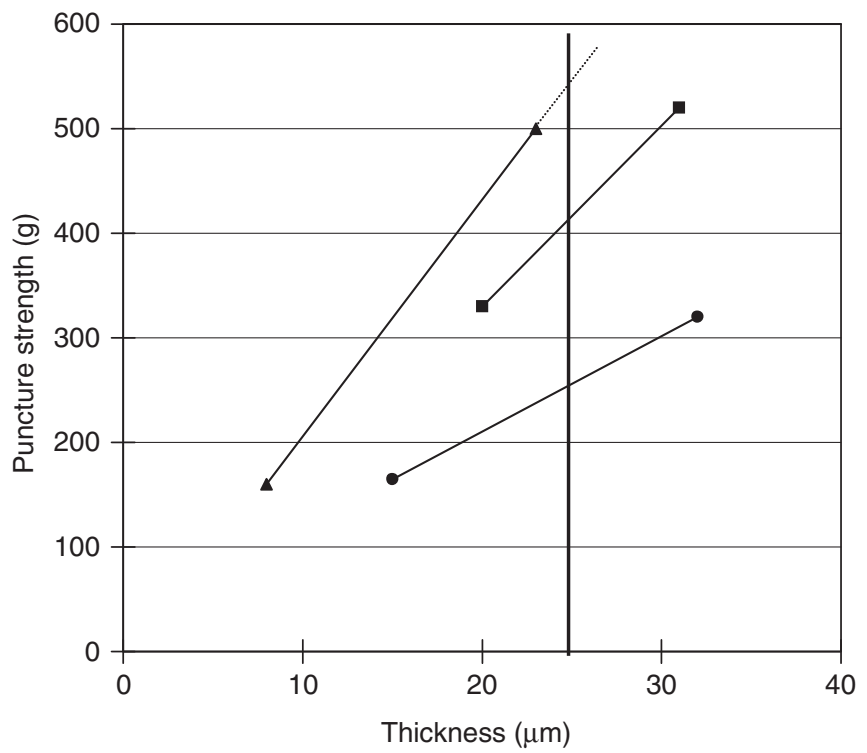

Figure 9 Effect of extension rate on the puncture strength of the films prepared by the phase separation/extension/extraction process. ${ }^{1}$ Symbols indicate the extension rate. $\bullet: 10 \%$ per second; $\mathbf{\square}: 100 \%$ per second and A: $300 \%$ per second. extension/extraction process. These results were caused during the increase in the extension rate; the molecule slip was reduced. The effect of the extension was clear. To examine the effect of the extension rate on the morphology of films; films obtained by the extension/ extraction process were observed using an electron microscope. These results are shown in Figure 11.

With an increase in the extension rate (10-600\% per second), the density of the film surface increased. The films that extended at a high rate were expected to have reduced molecule slip, increased strength and a very uniform structure.

The effect of the extension ratio on the strength of the films (including the molecular-weight effect) was also studied. A method similar to that of the experiment determining the effect of the extension rate was used. The results for the microporous films made by extraction/extension with two molecular weights are shown in Figure 12. The results for the microporous films made by extension/ extraction with two molecular weights are shown in Figure 13.

As a result of this experiment, three observations were made: (1) For both processes, the puncture strength increased with an increase in the extension ratio. (2) For the extraction/extension process, when the PE molecular weight increased from 600000 to 800000 , the puncture strength also increased. (3) In the extraction/extension process, the

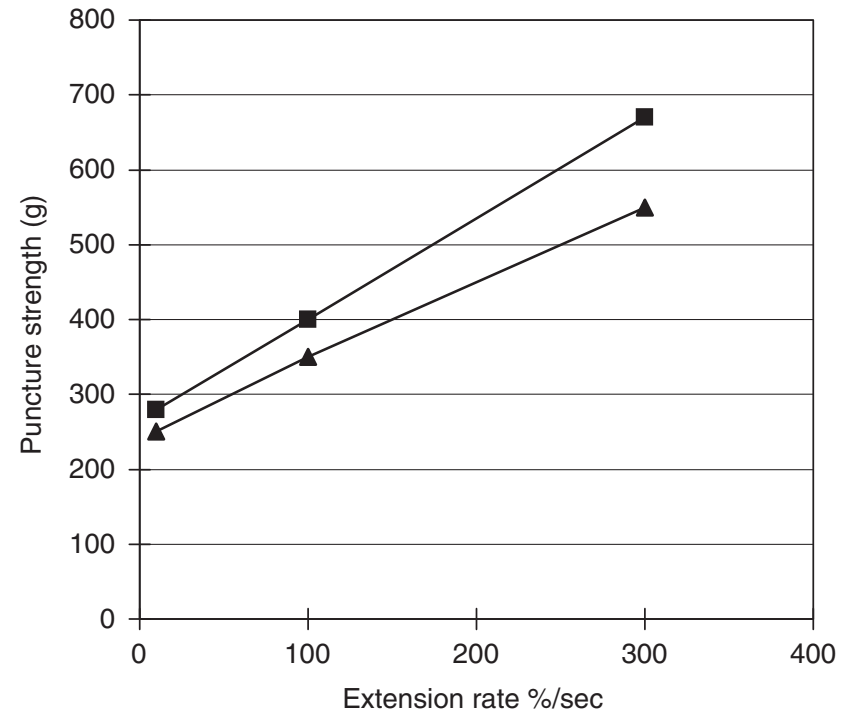

Figure 10 Effect of extension ratio on the puncture strength of the films prepared by extension/extraction $(\boldsymbol{\square})$ and extraction/extension $(\mathbf{\Lambda}){ }^{1}$

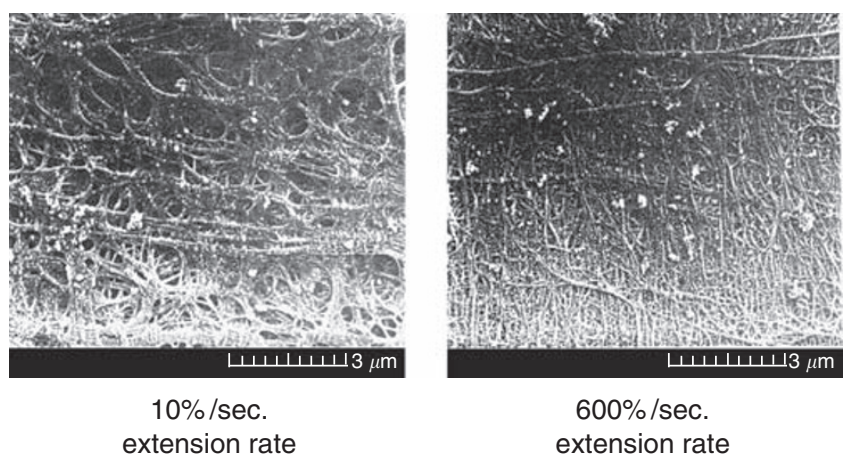

Figure 11 Scanning electron micrograph of the PE phase-separation membrane showing the effect of extension rate on the morphology of the membrane. ${ }^{1}$ 
range in which extension was possible was slightly narrower than the range in the extension/extraction process. When the extension ratio was more than about $5 \times 5$ ( 25 times) in extraction/extension and more than about $7 \times 7$ (49 times) in extension/extraction, a break during extension occurred.

The range of the extension ratio suggests that during extraction/ extension, extension was performed with voids present, and part of the extension force was used to expand the voids (as in the twocomponent systems). ${ }^{2}$ During the high-ratio extension, void expansion is assumed to have led to the break. During extension/extraction, no voids were present, and therefore, the extension effect was improved. Extension was assumed to be possible without break up

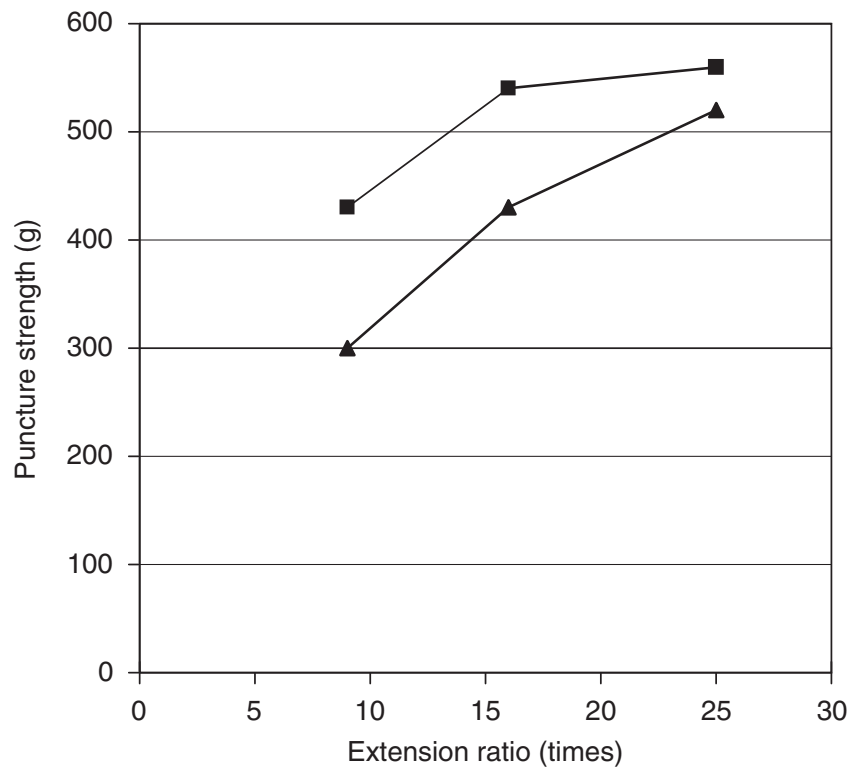

Figure 12 Effect of extension ratio on the puncture strength of the film prepared by the phase separation/extraction/extension process. ${ }^{1}$ Symbols indicate the molecular weight of PE. $\mathbf{\Lambda}: 6.0 \times 10^{4}$ and $\mathbf{a}: 8.0 \times 10^{4}$.

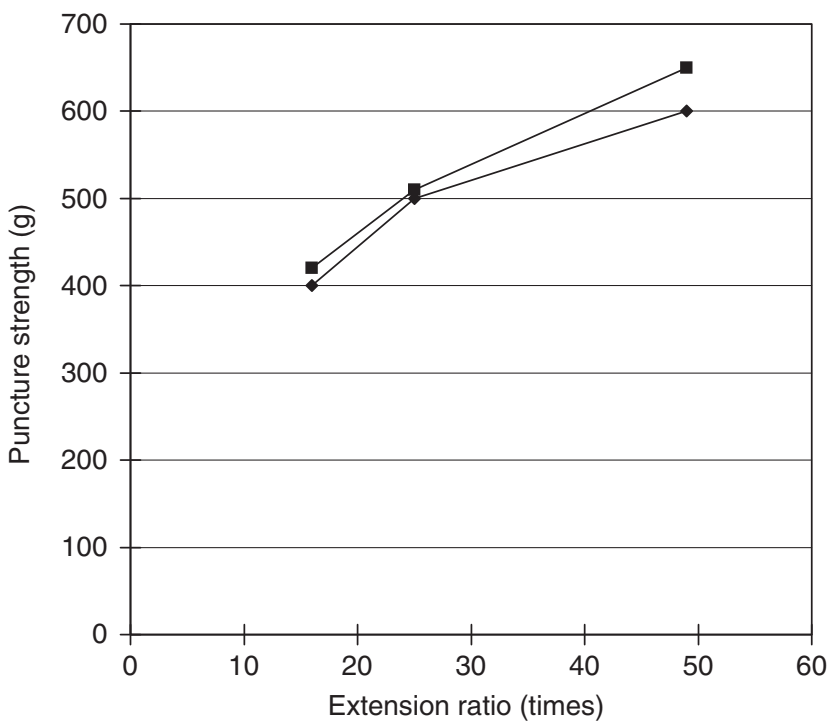

Figure 13 Effect of extension ratio on the puncture strength of the films prepared by the phase separation/extension/extraction process. ${ }^{1}$ Symbols indicate the molecular weight of PE. $\mathbf{\Delta}: 6.0 \times 10^{4}$ and $\mathbf{\square}: 8.0 \times 10^{4}$. to the higher ratio. Electron micrographs of the films obtained by both processes are shown in Figure 14. Films with a large pore diameter and a high void ratio (porosity) were obtained, and for extension/extraction, films with a small pore diameter and high strength were obtained (Table 3).

Manufacture of microporous PE films by three-component method conclusions. The estimation of the phase-separation state, the structure of phase-separation membranes and the processing (extension) of phase-separation membranes and the film structure were studied for three-component systems containing $\mathrm{PE}$, inorganic powder and a solvent.

Five conclusions were reached from these studies: (1) The phaseseparation state of the three-component system, which was not previously studied because the optical analysis of the phase-separation state was conventionally impossible, was successfully estimated from the change in viscosity (torque). (2) On addition of silica, silica is assumed to absorb the solvent, and the apparent PE concentration increased. As a result, the phase-separation temperature decreased. (3) With the addition of the inorganic powder, the viscosity of the system increased. Further, when silica with a large surface area was used, the viscosity of the system was further increased. (4) The phase-separation rate of the three-component system was slower than that of the twocomponent system. Therefore, the fusion of nuclei was slow, and the obtained film was a dense film without cell structures. Little change was observed in this system, even when silica was extracted. (5) When the extension of the phase-separation membrane was compared for the two processes, the extension/extraction film had a high strength and a small pore diameter, and the extraction/extension film had a low strength and a large pore diameter.

A method can be designed for producing a material that exhibits target film properties by selecting the extraction/extension, extension/ extraction and extension ratio based on the target values for the important properties of a separator (the strength and pore diameter).

\section{Properties of microporous PE films as battery separators}

The first use of a microporous film separator was in a Li primary battery. The polypropylene film had too high a melting point as an LIB separator, and therefore, when the temperature inside the battery is high, the polypropylene film cannot perform the fuse function. The Asahi Kasei Corporation first demonstrated that a microporous PE film is the optimum LIB separator with a fuse function. ${ }^{26}$

Surface observation. The physical properties of the films obtained by the wet process (the two-component and three-component methods in the thermally induced phase-separation films developed by Asahi
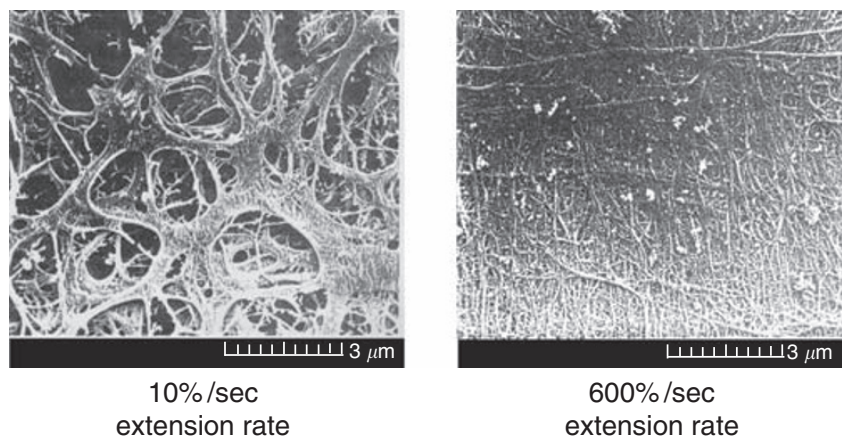

Figure 14 Differences in the morphology of PE membranes prepared by the extraction/extension process and the extension/extraction process. ${ }^{1}$ 
Kasei Corporation) and the dry process (the conventional method that produces porous films through extension-induced pore forming) were compared and studied.

The wet process involves three steps: (1) A polymer, a solvent and an inorganic powder are uniformly mixed at a high temperature. (2) The temperature is decreased to thermally induce the phase separation of the mixture into the polymer and the solvent+inorganic powder. (3) The solvent+inorganic powder phase is extracted. Before and after this step, extension is performed in some cases.

The dry process also involves three steps: (1) A polymer is extruded into a film at a high draft ratio. (2) The film is annealed for crystallization. (3) The film is extended at low temperature and then at high temperature to form pores at the crystal interface by extension stress.

Electron micrographs of the films obtained by these processes are shown in Figure 15. A microporous film with a large pore diameter was made for the first time by the three-component method. The mean pore diameter of the three-component film measured by the mercury intrusion method was $0.51 \mu \mathrm{m}$, which was about three times the mean pore diameter of the two-component film $(0.15 \mu \mathrm{m})$. The dry process (the extension-induced pore-forming method) produced films with a small mean pore diameter of $0.09 \mu \mathrm{m}$. The Garley value, which represents air permeability, was low for the three-component film, indicating the ease of air permeation for this film and a film (pore) structure through which ions easily permeate.

Comparison of physical properties of various films. The physical properties of the various films are shown in Table 4. The initial capacity retention rate after 500 cycles of charge and discharge was $85 \%$ for the three-component film, $80 \%$ for the two-component film and $70 \%$ for the porous film made by the dry process. The mechanism was not clear, but these results may be due to the large pore diameter of the three-component film. An oligomer may have been produced by the side reaction of the electrolytic solution during charge and

wet process

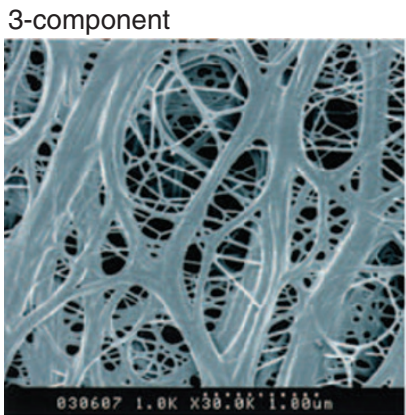

2-component

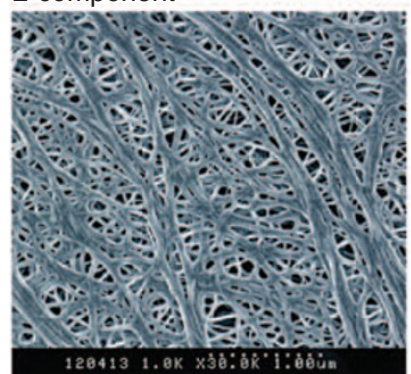

Figure 15 Electron micrograph of microporous membranes made by different processes. ${ }^{3}$ discharge and been deposited, but no clogging occurred. Therefore, the initial capacity retention rate was high.

Fuse temperature and film melting point (safety). The fuse temperature could be decreased for the three-component film by mixing in linear low-density PE (LLDPE). An example of the fuse temperature measurement is shown in Figure 16. Resistance value was measured, and the temperature was increased. The resistance value sharply increased around $135^{\circ} \mathrm{C}$. Without the addition of LLDPE, the resistance value sharply increased at about $140^{\circ} \mathrm{C}$. This increase in resistance value was caused by the clogging of pores in the microporous film. For one film, the resistance value sharply decreased around $150^{\circ} \mathrm{C}$. For another film, the resistance value did not decrease until $170^{\circ} \mathrm{C}$ at the last measurement, and these films contained UHMWPE. The film in which the resistance value decreased indicates that conduction occurred because of PE film break. The film in which the resistance value did not decrease until $170{ }^{\circ} \mathrm{C}$ was incorporated into a battery, and a safety test was performed.

Measurements were made of the pore structures of the films obtained by the wet process (the two-component method and the three-component method). The pore diameter for the three-component method was greater than the pore diameter for the two-component method. For the three-component method, the cycling properties were improved under certain battery-making conditions because the three-component film has a large pore diameter, and the deteriorated electrolytic solution did not easily clog the pores. In the separator with a large pore diameter, the discharge properties at low temperatures were good. The addition of LLDPE to the polymer composition decreased the fuse temperature. Owing to the decrease in fuse temperature, this polymer has a role as a safety device. When the temperature inside the battery increases because of overcharge, safety improves.

\section{Table 4 Physical properties of the microporous membranes ${ }^{3}$}

\begin{tabular}{lccc}
\hline & \multicolumn{2}{c}{ Melt process } & Dry \\
\cline { 2 - 3 } & Three-component & Two-component & process \\
\hline Thickness $(\mu \mathrm{m})$ & 25 & 25 & 25 \\
Porosity $(\%)$ & 49 & 40 & 45 \\
Garley value (s per $100 \mathrm{ml})$ & 100 & 250 & 300 \\
Mean diameter $(\mu \mathrm{m})$ & 0.51 & 0.15 & 0.09 \\
Resistance $\left(\Omega \mathrm{cm}^{-2}\right)$ & 0.9 & 1.1 & 0.9 \\
\hline
\end{tabular}

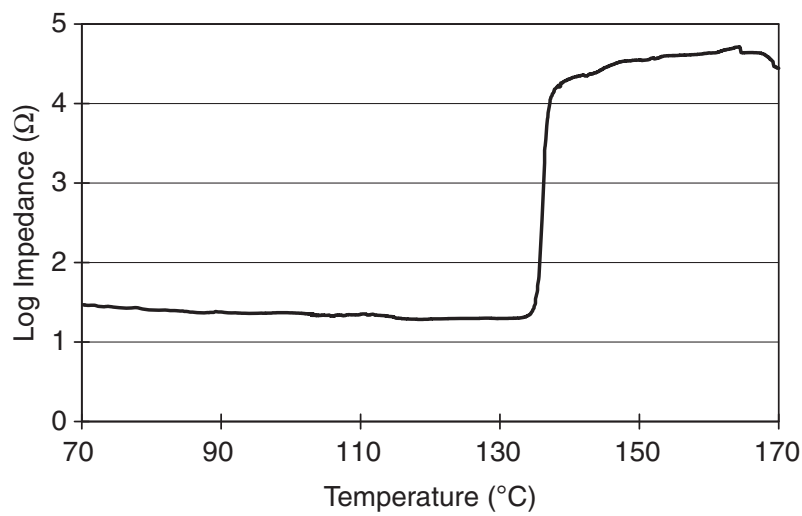

Figure 16 Temperature dependency of impedance showing the thermal stability of the separator. 
Properties of microporous PE films as battery separators conclusion. Four conclusions were reached by measuring the pore structures of the films obtained by the wet process (the two-component method and the three-component method). (1) The pore diameter produced by the three-component method was greater than the pore diameter produced by the two-component method. (2) For the three-component method, the cycle properties were improved under certain battery-manufacturing conditions because the three-component film has a large pore diameter, and the deteriorated electrolytic solution did not easily clog the pores. (3) For the separator with a large pore diameter, the discharge properties at low temperatures were good. (4) The addition of LLDPE to the polymer composition decreased the fuse temperature. Owing to this decrease in fuse temperature, this material is useful as a safety device. When the temperature inside the battery increases (for example, because the overcharge increases), safety improves.

\section{SOCIAL SIGNIFICANCE AND MARKET}

Social significance and importance

The output of LIBs in 2006 exceeded 600 billion yen on a global scale, and the number of LIBs produced increased to 2.3 billion. A shift from NiCd and NiMH batteries to LIBs has also occurred.

The LIB is present in almost $100 \%$ of all cellular phones, notebook computers, camcorders and game machines. The compact and lightweight cellular phones that contain LIBs have contributed to the spread of cellular phones and changed the information society.

LIBs are now necessary in modern society as a power supply for portable equipment such as cellular phones, notebook computers and digital cameras. The incorporation of a safety mechanism into the separator has improved the safety of LIBs and contributed to the spread of LIBs in the market. Safety has been the largest issue in the spread of LIBs.

In 2008, the number of cellular phones shipped around the world was about 120 million. Now, $\geqslant 4$ billion of the 6.7 billion people in the world benefit from cellular phones. Half of them, or 2 billion people, use a phone with a separator made of a microporous PE film. This technology has contributed to the mobile and information-oriented society by allowing the spread of LIBs.

This technology is a typical example of the advanced use and higher function of a polymer material in which PE, a general-purpose polymer, is processed in an advanced manner and used as a separator.

Owing to the efforts by the entire LIB-related industry (not only industries that produce separators) to improve safety, one accident among 25 million cells in 1997 decreased to one accident among 1.6 billion cells in 2005 .

\section{Markets, potentials and ripple effects}

LIBs maintain an overwhelming share of the market compared with other compact secondary batteries, and most compact and mobile equipment contains an LIB. LIBs have created and expanded markets, particularly for cellular phones and notebook computers, and LIBs have made a large contribution to the spread of these technologies.

With the future expansion of mobile equipment, a significant expansion of the LIB market is also expected.

The demand for separators is predicted to be proportional to the predicted demand for LIBs, and this expansion will continue in the future.

The Asahi Kasei Chemicals Corporation manufactures separators by phase-separation methods. The two-component method produces high-strength films, and the three-component method produces films with a large pore diameter. The Asahi Kasei Chemicals Corpora-

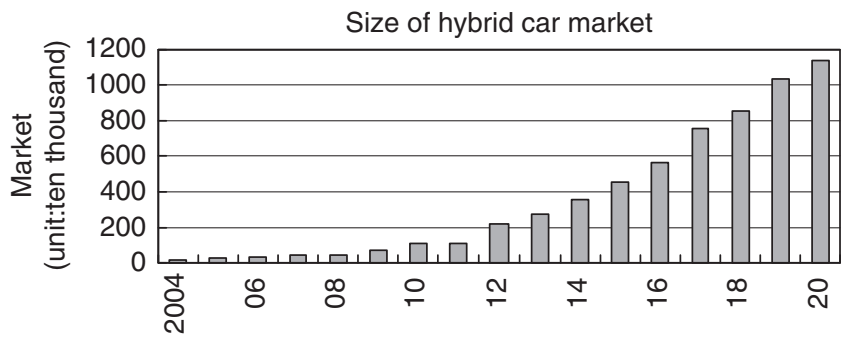

Figure 17 Prediction of the size of the hybrid car market cited from JP Morgan Securities, the Nikkei Business Daily, 22 May 2009, and Nikkei Business, 22 June 2009.

tion is the world's no. 1 company. About $80 \%$ of LIB separators are made by phase-separation methods.

LIBs are also expected to be used in batteries for hybrid cars. The spread of hybrid cars may be further accelerated because of a predicted rise in gasoline prices and increases in the number of cars produced per year to 10 million in 2020 (Figure 17). Nickel-hydrogen batteries are currently the mainstream battery, but LIB will be the mainstream battery in the future. Both automobile manufacturers and battery manufacturers now compete fiercely for development. Large-capacity charge and discharge over short time periods and more safety are required for LIBs in hybrid cars, and the development of LIBs and separators is being vigorously carried out. The development of LIB separators is expected to contribute to an energy-efficient and environmentally friendly society.

\section{CONCLUSIONS}

The development of this technology is summarized as follows:

(1) LIB is a technology developed by the Asahi Kasei Corporation in Japan and is a necessity in the modern, mobile society. LIBs will be a key form of technology for the future automobile and electric power industries and will contribute to a low-carbon society.

(2) The key to the spread of LIBs is a technology from the Asahi Kasei Corporation of Japan. This technology provides a safety function by using a microporous PE film for the separator.

(3) A microporous PE film has been produced by a thermally induced phase-separation method. No previous industrial manufacturing technology existed for this material.

(4) A technology for producing a LIB separator has been developed from polymer-manufacturing technologies and processing technologies, film technologies and phase-separation technologies, which are the core technologies of the Asahi Kasei Corporation.

(5) The features of this new technology are summarized as follows:

- A safety function is provided for the LIB separator.

- The optimum combination of high-density PE, linear LLDPE and UHMPE as a PE material is used to include a safety function in the separator by closing pores at low temperatures and maintaining the shape of the film at high temperatures.

- A production technology has been developed for the phaseseparation method. With this method, the pore diameter of a microporous film can be freely controlled. The large pore diameter film improves the performance of the LIB. This technology is the only known way to produce large pores.

- To obtain the large pore diameter film, phase-separation technology uses an inorganic powder to control the phase- 
separation state. An unprecedented, new academic area of three-component systems has been created in liquid-liquid phase separation for thermally induced phase separation, which was conventional for two-component systems. The industrial significance of this method has been shown.

- This technology uses thermally induced phase separation, which previously was only of interest in academic research, as an industrial technology for obtaining an industrial product, the microporous PE film (LIB separator).

(6) As microporous PE films for LIB separators were first manufactured, the share has always been ranked first in the world, and microporous PE films have contributed to the spread and innovation of LIB technology.

(7) The number of cellular phone subscribers in the world as of 2008 exceeded 4 billion. Two billion of these people benefit from microporous PE films for LIB separators made using this technology.

\section{ACKNOWLEDGEMENTS}

This research was performed in the Fundamental Research Laboratory of Natural and Synthetic Polymers, Designed Products Technology Research Laboratory, Industrial Membranes Technical Department, and Moriyama, Industrial Membranes Plant, Asahi Chemical Industry Co. Ltd. (These are their names at the time of writing this paper.) As a result of this research, industrialization was carried out at the Moriyama Industrial Membranes Plant. The authors express their appreciation to their superiors, colleagues and joint researchers at these places.

1 Yoneda, H., Hachiya, H. \& Adachi, M. Preparation of micro-porous polyethylene membrane by 3-component melt-process. Kobunshi Ronbunshu 64, 361 (2007).

2 Yoneda, H. \& Kondo, T. Preparation of micro-porous polyethylene membrane by 2component melt-process. Kobunshi Ronbunshu 64, 368 (2007).

3 Yoneda, H., Ikemoto, T. \& Kondo, T. Properties of battery separator of polyethylene micro-porous membrane. Kobunshi Ronbunshu 64, 394 (2007).

4 Yoneda, H. \& Masamoto, J. Production technology for lithium ion secondary battery and its application to the new field. Transactions of the Japan Society of Production Management 'Production Management' 13, 27 (2007).

5 Masamoto, J. \& Yoneda, H. Development of separator for lithium ion secondary battery and its application to the new field. Memoirs of Fukui Univercity of Technology 37, 265 (2007).

6 Shirakawa, H. \& Ikeda, S. Infrared spectra of poly(acetylene). Polym. J. 2, 231 (1971).
7 Shirakawa, H. \& Ikeda, S. Simultaneous polymerization and formation of polyacetylene film on the surface of concentrated soluble Ziegler-type catalyst solution. J. Polym. Sci., Polym. Chem. 12, 11 (1974).

8 Shirakawa, H., Louis, E. J., MacDiarmid, A. G., Chiang, C. K. \& Heeger, A. J. Synthesis of electrically conducting organic polymers: halogen derivatives of polyacetylene, $(\mathrm{CH}) \mathrm{x}$. J. Chem. Soc., Chem. Commun 578 (1977).

9 Nigrey, P. J., David, M., Nairns, D. P., MacDiarmid, A. G. \& Heeger, A. J. Lightweight rechargeable storage batteries using polyacetylene, $(\mathrm{CH}) \mathrm{x}$ as the cathode-active material. J. Electrochem. Soc. 128, 1651-1654 (1981).

10 MacInnes Jr, D., Drug, M. A., Nigrey, P., Nairns, D. P., MacDiarmid, A. G. \& Heeger, A. $J$. Organic batteries: reversible $n$ - and $p$ - type electrochemical doping of polyacetylene, (CH)x. J. Chem. Soc., Chem. Commun. 317-319 (1981).

11 MacDiarmid, A. G., Nigrey, P. J., MacInnes, Jr, D., Nairns, D. P. \& Heeger, A. J. Electrochemistry of polyacetylene, $(\mathrm{CH}) \mathrm{x}$ : lightweight rechargeable batteries using $(\mathrm{CH}) \mathrm{x}$ as the cathode-active material. Organic Coating and Plastic Chem. 44, 372 (1981).

12 Yoshino, A. \& Sanechika, K. Secondary Battery, Japanese Unexamined Pat. 60-127669 (1985), assigned to Asahi Kasei.

13 Yoshino, A. \& Yomo, M. Secondary Battery, Japanese Pat. 2668678 (1997), assigned to Asahi Kasei.

14 Yoshino, A. Carbonaceous material for negative electrode of lithium ion battery. TANSO 45, 186 (1999)

15 Lloyd, D. R., Kim, S. S. \& Kinzer, K. E. Microporous membrane formation via thermallyinduced phase separation. II. Liquid-liquid phase separation. J. Memb. Sci. 64, 1 (1991).

16 Lloyd, D. R., Kinzer, K. E. \& Tseng, H. S. Microporous membrane formation via thermally induced phase separation. I. Solid-liquid phase separation. J. Memb. Sci. 52, 239 (1990).

17 McGruire, K. S., Laxminarayan, A. \& Lloyd, D. R. Kinetics of droplet growth in liquidliquid phase separation of polymer-diluent system: experimental results. Polymer 36, 4951 (1995).

18 Hayashi, K., Matsuyama, H., Teramoto, M. \& Kubota, N. Effect of inorganic materials addition for preparation of micro-porous polyethylene hollow fiber membrane via thermally induced phase separation Proceedings of the Annual Meeting of The Society of Chemical Engineers, Japan, pp. 649, (in Japanese) (2003).

19 Pathmamanoharan, C., De Hec, H. \& Vrij, A. Phase separation in mixtures of organophilic spherical silica particles and polymer molecules in good solvents. Colloid Polym. Sci. 259, 769 (1981).

20 Matsuda, K. \& Doi, Y. Polyethylene microporous film for lithium battery separator, Japanese Unexamined Pat. 2-94356 (1990), assigned to Asahi Kasei.

21 Doi, Y., Kaneko, S., Hanamura, T., Fujii, O. \& Yoshitake, K. Porous membrane, Japanese Examined Pat. 58-19689 (1983), assigned to Asahi Kasei.

22 Isaacson, R. B. \& Biernbaum, H. S. Process for preparing microporous film, US Pat. 3,338,764 (1971), assinged to Celanease.

23 Hojuyama, I. \& Sogo, H. Polyethylene Millipore membrane, Japanese Pat. 3258737 (2001), assigned to Asahi Kasei.

24 Doi, Y., Kohno, M. \& Yoshitake, K. Porous polyolefin resin membrane, alkali battery separator, and microporous filter, Japanese Examined Pat. 59-37292 (1983), assigned to Asahi Kasei.

25 Kamei, E. \& Shinomura, Y. Process of producing porous thermoplastic resin articles, US Pat. 4,563,317 (1986), assigned to Ube Industries.

26 Yoshino, A., Nakanishi, K. \& Ono, A. Explosion proof secondary battery, Japanese Pat. 2642206 (1997), assigned to Asahi Kasei.
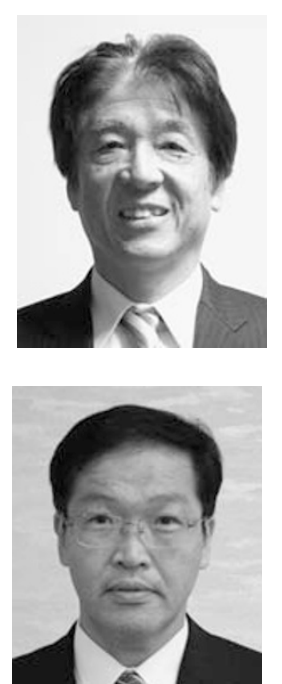

Haruyuki Yoneda was born in 1951 in Osaka, Japan. He received his BS and MS degrees in Chemistry from Kyoto University. He obtained his PhD degree in Engineering in 2006 from Fukui University of Technology under the guidance of Professor Junzo Masamoto, who had been in Asahi Kasei. He joined the Asahi Chemical Industry in 1976. He was engaged in the R\&D of the PE catalyst He was the general manager of the Hipore Plant and R\&D Department. He is now the executive officer and general manager of the center's R\&D laboratories.

Yoshifumi Nishimura was born in 1959 in Hyogo, Japan. He received his BS and MS degrees in Chemistry from Kyoto University under the supervision of Professor Michio Kurata. He joined the Asahi Chemical Industry in 1984. He has worked in this field since 1989. He is now the general manager of the Hipore Plant. 


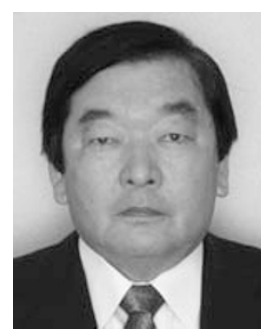

Yoshinao Doi was born in 1946 in Tokyo, Japan. He received his BS and MS degrees in Chemistry from Keio University under the supervision of Professor Mitsuo Fujii in Doi's biography. He joined the Asahi Chemical Industry in 1971. He is one of the inventors of the three-component systems. He is now the technology adviser of the Microza \& Water Processing Division.

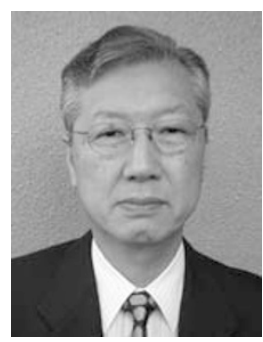

Masahiko Fukuda was born in 1942 in Shiga, Japan. He joined the Asahi Chemical Industry in 1960. He then joined the Hipore sales division in 1982 and developed new avenues for Hipore with the LIB separator. He was the general manager of the Hipore Sales \& Marketing Department from 1998 to 2002.

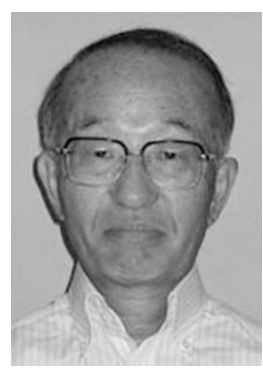

Mitsuo Kohno was born in 1941 in Tokyo, Japan He received his BS degree in Chemistry from Keio University. He joined the Asahi Chemical Industry in 1964. He is one of the inventors of the three-component system. He was the director and senior executive officer, corporate R\&D, of Asahi Kasei. He is now at the National Institute of Advanced Industrial Science \& Technology. 